REVISTA

ACADEMIA Y 2019

VIRTUALIDAD VOL. 12(1)

Enero-junio 2019

ISSN-e: 2011-0731

pp. 7-30

DOI: https://doi.org/10.18359/ravi.3618

\title{
Las competencias digitales en estudiantes de doctorado. Un estudio en dos universidades mexicanas ${ }^{1}$
}

\author{
Armando Sánchez-Macías ${ }^{2}$ y María Guadalupe Veytia-Bucheli
}

Recibido: Agosto 22 de 2018
Evaluado: Octubre 09 de 2018
Aceptado: Octubre 26 de 2018

Resumen Las competencias digitales representan el conocimiento, la habilidad y la conciencia indispensables para el desenvolvimiento efectivo de los sujetos en la sociedad del conocimiento. El objetivo de la presente investigación es caracterizar el nivel de competencia digital en los estudiantes de doctorado y las variables sociodemográficas que pueden influir en este. Es una investigación de enfoque cuantitativo, descriptivo-correlacional, transversal y no experimental. Se estudió una muestra de estudiantes del doctorado en Administración y Educación de dos universidades mexicanas. Se utilizó el "Cuestionario de Competencias Digitales", versión en español, que fue sometido a pruebas estadísticas para medir su consistencia y validez interna. Se encontró que los estudiantes de doctorado no tienen un mayor nivel de competencias digitales solo por el hecho de pertenecer a este nivel educativo y que el género de estos tampoco es un factor determinante. Además, se encontró evidencia parcial en varias dimensiones (relaciones estadísticamente significativas), que sugieren que pertenecer a un programa que se imparte a distancia incentiva las competencias digitales en comparación a cuando un programa se estudia de manera semipresencial (b-learning).

Palabras clave: competencias digitales; posgrado; estudiantes de doctorado; TIC

1 Artículo de investigación científica y tecnológica.

2 Doctor en Educación en la Universidad Abierta de Tlaxcala, México. Profesor del programa de Licenciatura en Administración; Coordinación Académica Región Altiplano Oeste de la Universidad Autónoma de San Luis Potosí de México. Correo electrónico: armando.sanchez@uaslp.mx

3 Doctora en Sistemas y Ambientes Educativos de la Universidad Virtual de Guadalajara. Profesora del Instituto de Ciencias Sociales y Humanidades de la Universidad Autónoma del Estado de Hidalgo: Pachuca, Hidalgo. Correo electrónico:maria_veytia@uaeh.edu.mx 


\title{
Digital Competences in Ph.D. Students: A Study on Two Mexican Universities
}

\begin{abstract}
Digital competences represent the knowledge, skills, and awareness required for effectively developing subjects within the knowledge society. Within this context, this quantitative, descriptive-correlational, cross-sectional, and non-experimental research study seeks to characterize digital competence levels in Ph.D. program students, as well as the sociodemographic variables that may exert influence on these levels. For these purposes, the Spanish version of the "Digital Competence Assessment" was applied to a sample of Ph.D. students in administration and education selected from two different Mexican universities. Prior to its application, this assessment had been subjected to statistical tests to measure its consistency and internal validity. Based on the results, Ph.D. students do not exhibit a higher level of digital competences simply because they are in this academic level, and their gender is not a determining factor either. Moreover, partial evidence was found in several dimensions (statistically significant relationships), which suggests that distance education programs foster digital competences as opposed to blended learning (b-learning) programs.
\end{abstract}

Keywords: Digital Competences; Graduate Programs; Ph.D. Students; ICT

\section{Competências digitais em alunos de doutorado: um estudo de duas universidades mexicanas}

Resumo: As competências digitais representam o conhecimento, as habilidades e a conscientização necessários para o desenvolvimento efetivo dos indivíduos dentro da comunidade do conhecimento. Dentro deste contexto, este estudo quantitativo, descritivo-correlacional, transversal e não experimental busca caracterizar os níveis de competência digital em alunos de programas de doutorado, bem como as variáveis sociodemográficas que podem exercer influência sobre esses níveis. Para esses propósitos, a versão em espanhol da "Avaliação de Competências Digitais" foi aplicada a uma amostra de alunos de programas de doutora em administração e educação selecionada de duas universidades mexicanas diferentes. Antes de sua aplicação, esta avaliação foi submetida a testes estatísticos para medir sua consistência e validade interna. Com base nos resultados, os alunos de programas de doutorado não exibem um nível mais alto de competências digitais apenas porque estejam nesse nível acadêmico, e seu gênero também não constitui fator determinante. Além disso, foram encontradas evidências parciais em várias dimensões (relações estatisticamente significativas), o que sugere que os programas de educação à distância promovem as competências digitais em oposição aos programas de aprendizagem combinada (b-learning).

Palavras-chave: Competências digitais; programas de pós-graduação; alunos de doutorado; TIC 


\section{Introducción}

La sociedad actual se caracteriza por el acceso que se tiene a la información en diversos formatos, tanto físicos como electrónicos. Hace algunos años era complejo encontrar información sobre determinados temas, a diferencia de hoy en día, gracias al empleo de las Tecnologías de la Información y la Comunicación (TIC). La barrera del pasado se ha derribado, pero actualmente se presentan nuevos retos: fortalecer los procesos de búsqueda, selección y empleo de la información, en los que se usen habilidades como el análisis, la síntesis y la interpretación de los datos. De esta manera, se trabajarían interpretaciones con las informaciones obtenidas, pues estas lograrían adquirir sentido y significado para quien las utilice. Sería este el tránsito de la información al conocimiento (Barroso, 2013).

Es cada vez más frecuente en el ámbito académico escuchar los términos "sociedad de la información" y "sociedad del conocimiento". Es importante tener en cuenta que, aunque estos son, en algunas ocasiones, empleados por autores y organismos internacionales como sinónimos, cada uno de los términos posee rasgos únicos - aunque existe un vínculo entre ellos-, que se deben identificar.

La sociedad de la información se basa en el progreso tecnológico; en esta, los sujetos utilizan sus habilidades principalmente para identificar, transmitir y difundir la información, a partir del empleo de diversos formatos, como los textos, los videos o los audios. Por otra parte, la sociedad del conocimiento se concentra en otro nivel, en las dimensiones educativas, sociales, éticas y políticas, que favorecen la construcción social y el domino de saberes, a partir de la información accesible, y que son transferibles a diversos contextos, en los que los sujetos desarrollan competencias, es decir, movilizan sus saberes conceptuales, procedimentales y actitudinales. De acuerdo con esta comparación, la sociedad de la información constituye un instrumento para trabajar en la sociedad del conocimiento. La relación entre ambas sociedades conforma un círculo virtuoso, en el que se generan avances educativos a corto, mediano y largo plazo
(Mínguez y Hernández, 2013; Sánchez, 2015; Didriksson, 2007; Unesco, 2005).

Desde la perspectiva de Manuel Castells (1997), la sociedad del conocimiento se define como el conjunto de transformaciones económicas y sociales que modifican la base material de la sociedad. En este proceso de cambio, el empleo de las TIC constituye un factor clave, debido al incremento de información que se está generando, así como a los procesos de comunicación que evolucionan tanto de manera sincrónica como asincrónica.

$\mathrm{Al}$ abordar, entonces, el tema de las TIC y, con este, el de la revolución digital que se está generando en la actualidad, Ola Erstad (2010) destaca cuatro ámbitos en los cuales existe un impacto considerable: una cultura de participación, a través del empleo de las redes y los medios; el acceso a la información de forma rápida y en diversos formatos; el incremento de las posibilidades de comunicación, a través del correo electrónico, mensajes, chats, entre otros, y la producción y difusión del conocimiento, que permiten transitar de una sociedad de la información a una sociedad del conocimiento.

Ante las demandas de la sociedad actual y los cambios que se han generado con el empleo cada vez más frecuente de las Tic, la educación y los procesos de enseñanza - aprendizaje en los diferentes niveles educativos y modalidades - se enfrentan a nuevos desafíos. Es vital, por ello, la construcción de modelos, entornos, recursos y mediaciones que respondan con eficacia y eficiencia a las necesidades y problemáticas de la sociedad actual (Area, 2010; Durat y Mengual-Andrés, 2014; Roblizo y Cózar, 2015)

\section{Marco referencial}

El concepto de competencia se caracteriza por ser polisémico, ambiguo y un tanto complejo, ya que se ha definido a partir de diversos contextos, disciplinas, ámbitos y en distintos momentos históricos. Aunque se origine en el ámbito laboral, en la actualidad es cada vez más frecuente escucharlo en el ámbito académico. En este sentido, Frade (2007) asegura que la vinculación entre ambos ámbitos se estableció a causa de los requisitos que 
las instituciones educativas debían cumplir para responder a las demandas laborales.

Desde la perspectiva de Torrado (1998), la competencia representa "una acción situada, que se define en relación con determinados instrumentos mediadores" (p. 42), y se orienta a un saber hacer. Sin embargo, Levy-Leboyer (1997) considera que las competencias se dirigen hacia el saber ser, pues las define como "repertorios de comportamientos que algunas personas dominan mejor que otras, lo que las hace eficaces en una situación determinada" (p. 54). Algunos otros autores destacan la importancia de generar un equilibrio entre el $s a$ ber conocer, hacer y ser, al definir la competencia como "la capacidad para movilizar varios recursos cognitivos para hacer frente a un tipo de situaciones" (Perrenaud, 2007, p. 8). Por su parte, Zabala y Arnau (2007, p. 43) destacan, en su conceptualización, la capacidad para llevar a cabo tareas o resolver situaciones problemáticas de manera eficaz y eficiente en un contexto específico. De ahí que sea necesario movilizar tanto los saberes conceptuales como los procedimentales y actitudinales de manera interrelacionada.

Es relevante mencionar que las competencias son comportamientos observables, que requieren "ser comprobados en la práctica mediante el cumplimiento de unos criterios de desempeño" (Huerta, Pérez y Castellanos, 2000, p. 3). Es por ello que estas se reconocen como parte de un proceso gradual, que se va enriqueciendo a lo largo de la vida del ser humano. Tobón (2014) establece desde un enfoque socioformativo cuatro niveles de formación de competencias: el primero es el nivel bajo-receptivo, que se vincula con las siguientes acciones: identificar, reconocer, registrar, concentrarse, describir y definir; el segundo es el básico-resolutivo, en el que se llevan a cabo procesos en los que el sujeto comprende, resuelve, ejecuta, planifica, elabora, diagnostica, implementa y realiza; el tercero es el alto-autónomo, en el que se argumenta, explica, autorregula, mejora, formula, critica, analiza y articula, y, por último, está el nivel superior estratégico, asociado a la capacidad de creación, innovación, vinculación, adaptación y teorización.
Con base en los planteamientos anteriores, se observa con precisión que conceptualmente se ha transitado de una perspectiva reduccionista a una holística e integral. El proyecto Definition and Selection of Competencies (2000) define este término más allá de los conocimientos y las destrezas, pues involucra, más bien, la habilidad para enfrentar demandas complejas, a través de la movilización de una serie de recursos que le permiten al sujeto responder a las problemáticas en un determinado contexto. Así, cada competencia está constituida por tres requisitos principales: en primer lugar, esta debe contribuir en la generación de resultados valiosos para la sociedad; debe estimular a los sujetos para que enfrenten retos y problemáticas en diversos contextos, y debe ser relevante tanto para los especialistas como para los sujetos en general.

En la actualidad existen nuevos entornos educativos, que se caracterizan por el empleo de las TIC. De este modo, el nivel de dominio de competencias comunicativas, éticas, pedagógicas, de gestión e investigativas ya no es suficiente para un desempeño eficaz y eficiente de los individuos en la sociedad del siglo xxI; el manejo de las competencias tecnológicas, así como de las digitales, ha pasado de ser recomendable a necesario, ya que solo por medio de este se constituyen competencias clave para el aprendizaje permanente, para la realización de actividades y para la resolución de problemáticas que se presentan en los diversos contextos en donde se desenvuelve el ser humano (Rangel, 2015).

De acuerdo con los argumentos presentados por De Pablos (2010), en la actualidad se observa una acumulación de información de manera acelerada, pues es evidente la velocidad con la que esta se transmite a través de diversos medios y formatos electrónicos; se trata, por demás, de un fenómeno que ha superado las barreras del tiempo y de las fronteras. Para afrontar a este no son, por lo tanto, suficientes los procesos de búsqueda, identificación y organización de la información, sino que se debe incentivar la generación de conocimientos y la aplicación de forma creativa de saberes con el fin de hacer parte de la resolución de problemáticas y demandas, presentadas en los diversos espacios en los que se desempeñan los individuos. 
Las formas digitales de la información y comunicación están transformando el significado de estudiar, investigar, expresarse, pensar, producir y difundir conocimiento en diversos formatos. En consecuencia, los lugares de trabajo y de estudio también están cambiando, y el aprendizaje a través de procesos de mediación tecnológica se ha incrementado considerablemente en los últimos años. Además, el aprendizaje ya no solo es para la escuela, pues se ha convertido en un camino que se recorre durante toda la vida, por medio de procesos formales presenciales, semipresenciales y a distancia, así como de procesos informales en los diversos espacios de acción humana. Es, entonces, la competencia digital cada vez más necesaria para que el individuo se desarrolle en los diversos contextos. No obstante, todavía existen confusiones en torno a la capacidad de los estudiantes a la hora de emplear tecnologías para el manejo de la información, confusiones en lo que respecta a un aprendizaje de estos mediado por lo tecnológico, y que hacen que no se aproveche al máximo el potencial de la tecnología (Littlejohn, Beethman y McGill, 2012).

Ante la eminente relevancia de la competencia digital, la conceptualización y caracterización de esta se ha diversificado, tanto en los autores como en los organismos nacionales e internacionales. No existe una definición única. Por ejemplo, el Instituto de Tecnologías Educativas (ITE, 2011) la define como una capacidad que le permite al ser humano disponer de habilidades para buscar, obtener, procesar y comunicar información susceptible de transformarse en conocimiento.

Para la Unesco (2008), en el documento "Estándares de competencias TIC para docentes", se destacan elementos clave de la competencia digital:

Para vivir, aprender y trabajar con éxito en una sociedad cada vez más compleja, rica en información y basada en conocimiento, los estudiantes y los docentes deben utilizar la tecnología digital con eficacia. En un contexto educativo sólido, las Tecnologías de la Información y la Comunicación pueden ayudar a los estudiantes a adquirir las capacidades necesarias para llegar a ser: competentes, para utilizar Tecnologías de la Información y la Comunicación: buscadores, analizadores y evaluadores de información; solucionadores de problemas y tomadores de decisiones, usuarios creativos y eficaces de herramientas de productividad; comunicadores, colaboradores, publicadores y productores; y ciudadanos informados, responsables y capaces de contribuir a la sociedad (p. 2).

Por su parte, la DIGCOMP (2014) describe la competencia digital como el conjunto de conocimientos, habilidades, actitudes y estrategias que permiten hacer conciencia del uso de las TIC y de los materiales y recursos digitales, con el fin de realizar diversas tareas, resolver problemas, comunicar y gestionar la información y generar conocimiento, tanto de manera individual como de forma colaborativa. Así, todo este proceso no se limita al consumo de la información, sino que se extiende hacia la gestión del conocimiento.

Carrera y Coiduras (2012) y Flores (2014) comparten esta postura. Empero, hacen énfasis en la importancia de que maestros y estudiantes empleen las TIC en situaciones cotidianas; aquellas permitirán incrementar, de este modo, los niveles de logro de los sujetos, así como la comunicación de estos en diversos escenarios de interacción, para fortalecer el desarrollo del pensamiento de orden superior, a partir de la participación en comunidades de aprendizaje con sus colegas y compañeros.

En este sentido es que Mercè Gisbert (2011), también en su artículo junto con Francesc Esteve (2011), confirma que la competencia digital se considera clave en la sociedad actual. Esta se desarrolla durante la vida del ser humano y, en el ámbito educativo actual, es una tarea prioritaria. De ahí que un diagnóstico que permita valorar el nivel de competencia digital con el que llegan los estudiantes a las aulas se considere una de las actividades fundamentales para llevar a cabo. De igual mane$\mathrm{ra}$, se buscan las estrategias adecuadas para incrementar el desarrollo de esta competencia durante el proceso formativo de los alumnos, por medio de una perspectiva transversal en la que se involucren las diversas disciplinas que forman parte de su plan de estudios.

En su análisis, Anusca Ferrari (2013) plantea una propuesta de cinco áreas con el fin de 
comprender la complejidad de la competencia digital. Estas son: información, comunicación, creación de contenido, seguridad y solución de problemas. Es evidente que las dos primeras áreas de esta clasificación han tenido un mayor desarrollo para los usuarios de las TIC. Sin embargo, hace falta fortalecer lo relacionado con la creación de contenido, seguridad y solución de problemas, pues muchas veces la competencia digital de los individuos se concentra únicamente en el consumo de información y deja de lado la construcción de conocimiento y, por ende, la creación innovadora de contenido.

Por su parte José Janssen y Slavi Stoyanov (2012) definen las competencias digitales como un conglomerado de conocimientos, habilidades y actitudes, vinculadas a varios propósitos (comunicación, expresión creativa, administración de la información, desarrollo personal, etc.), dominios (usos en la vida cotidiana, trabajo, privacidad y seguridad, aspectos legales) y niveles (niveles cognitivos y niveles de eficiencia).

Por otra parte, la Unesco (2011) establece su propio marco de referencia de la competencia digital, a través de una clasificación de tres niveles de adquisición. Así, destaca la complejidad de esta y su naturaleza como competencia, pues se trata de un proceso que se desarrolla a lo largo de la vida. El primer nivel se refiere a la alfabetización digital, que permite incrementar el uso eficiente de la tecnología; el segundo nivel alude a la profundización en el conocimiento de diversos ámbitos disciplinares, a partir del empleo de las TIC, y finalmente, en el tercer nivel, se genera la construcción del conocimiento, gracias a lo que proporciona el ya existente, para aplicarlo a situaciones y contextos concretos.

Manuel Area (2010) plantea y expone cinco postulados para formar competencias digitales en la educación superior. Los enumeramos a continuación:

1. La producción de conocimientos se está incrementando considerablemente en las diversas áreas y disciplinas del saber, por lo que no solo se requiere formar para la vida, sino formarse durante toda la vida y, de esta manera, adquirir tanto los conocimientos como las habilidades y destrezas para actualizarse de manera permanente.

2. Ha crecido el número y la diversidad de fuentes que permiten almacenar, organizar y difundir la información. Por ejemplo, a través del empleo de bases de datos, bibliotecas virtuales, revistas electrónicas, portales web, por mencionar algunas.

3. Los modelos pedagógicos en la actualidad se orientan más hacia un aprendizaje activo, centrado en el estudiante, en el que se recuperan los saberes previos y se vinculan con los nuevos conocimientos, para que estos adquieran significado y sentido.

4. A partir del empleo de las TIC, se ha incrementado la diversidad de recursos pedagógicos y tecnológicos que permiten respetar los diferentes ritmos y estilos de aprendizaje de los estudiantes, ya que se presenta la información en una variedad de formatos que van desde documentos escritos, audios o videos, por mencionar algunos.

5. El empleo de Ambientes Virtuales de Aprendizaje (AvA) es cada vez más común en el desarrollo de procesos de enseñanza-aprendizaje en las distintas modalidades: presencial, semipresencial y a distancia, las cuales enriquecen el trabajo que se desarrolla tanto por los estudiantes como por los docentes.

Ante esta realidad, el manejo de las competencias digitales en los estudiantes del siglo xxı favorece los procesos de la búsqueda, identificación, organización, análisis, selección de información de manera eficiente, ética y legal; la interconexión entre personas de diversas partes del mundo, tanto de manera sincrónica como asincrónica; favorece también que este tipo de acciones permita transformar la información en conocimiento, así como comunicarla y compartirla en distintos entornos, tanto presenciales como digitales (Pons, 2010; Pérez y Rodríguez, 2016; Arias, Torres y Yáñez, 2014). Jorge Luis Bonilla Tena y Arturo Moctezuma Nava (2017) hacen, del mismo modo, énfasis en los aspectos éticos y legales, pero también en los no 
discriminatorios de la integración de las TIC y en la formación de competencias digitales. Gracias a esto se dimensiona el fenómeno en su justa medida como herramienta al servicio de la educación.

Pilar Colás Bravo, Jesús Conde-Jiménez y Salvador Reyes-de Cózar (2017, p. 9) afirman que no existe aún consenso acerca de "una definición de competencia digital que satisfaga a todos los colectivos, organismos e investigadores especializados en materia educativa". Sin embargo, destacan la importancia de alejarse de concepciones mecanicistas que solo tengan en cuenta las habilidades para utilizar las TIC, y prefieren, más bien, esta postura, según la cual la competencia digital es

una habilidad que se configura en torno a la búsqueda, selección, proceso y aplicación de la información a partir de una cantidad de fuentes, sumando, además, la capacidad de utilizar estratégicamente esta información para mejorar la posición de las unidades de la sociedad (Van Dick, 2005, citado en Colás Bravo, Conde Jiménez y Reyes de Cózar, 2017).

Por su parte, Paz Prendes Espinoza, Isabel María Solano Fernández, José Luis Serrano Sánchez, Víctor González Catalayud y María del Mar Román García (2018) distinguen entre las competencias digitales del profesorado, que se relacionan con la profesionalización de este, y las del alumnado, que se relacionan con las capacidades de aprendizaje y sus posibilidades para incluirse de manera plena en la sociedad. Para Claudia Islas Torres y Sergio Franco Casillas (2018), el éxito del sistema educativo depende, en gran parte, de la adecuada gestión de las competencias en el mundo digital.

La competencia digital que en un primer momento se orientaba más hacia aspectos tecnológicos, en la actualidad se ha convertido en una competencia mucho más compleja, pues, como se observa en las definiciones anteriores, es la suma y la movilización de conocimientos, habilidades y actitudes de los aspectos tanto tecnológicos como informacionales, multimedia y comunicativos, lo cual es resultado de una alfabetización tecnológica funcional que permite superar la mirada instrumental y generar procesos productivos.
Los postulados referidos revelan la complejidad de la competencia digital y la necesidad de emplearla en la sociedad actual, tanto en los espacios formales, las instituciones educativas, por ejemplo, como en los espacios informales, en los que se desenvuelven los estudiantes en sus diversas actividades. De este modo, se proporcionan mayores recursos para dar respuesta a las demandas y problemáticas que se les presentan a los sujetos en su vida cotidiana, académica y laboral.

Las prácticas basadas en el conocimiento digital son relevantes y generadoras de significado y sentido para cada sujeto, principalmente de acuerdo con sus intereses y con sus saberes previos, con la motivación y los entornos en los cuales se desenvuelve. Dichas prácticas serán valiosas dependiendo de la utilidad con la que sean empleadas para resolver distintas situaciones, y en la medida en que permitan responder a las nuevas problemáticas presentadas en la sociedad actual (Goodyear y Ellis, 2008).

Sin embargo, el empleo de las TIC por parte de los estudiantes no asegura el desarrollo de la competencia digital, pues estos pueden utilizar frecuentemente diversas herramientas tecnológicas y, sin embargo, carecer de capacidades que les permitan analizar, sintetizar o reflexionar sobre la información y generar conocimiento. Otra cuestión relevante es que las herramientas tecnológicas se aprovechan en un bajo porcentaje, si se consideran todas las funciones o potencialidades con las que estas cuentan. El papel del docente continúa siendo clave para el desarrollo del proceso de enseñanza-aprendizaje con apoyo de las TIC (Sharpe, 2010; Margayan, et. al., 2011; Hardy, et. al., 2009).

En esta investigación se asumen las categorías de competencia digital propuestas por Janssen y Stoyanov (2012) y adaptadas por José Iram Zúñiga Lobato (2016). Así se busca crear una definición multidimensional de la competencia digital. En este sentido, se establecen dos categorías: "competencias digitales básicas, indispensables para la cultura y la ciudadanía digital y competencias digitales transversales (de nivel intermedio), útiles en los procesos de aprendizaje, construcción del conocimiento y como medio para la adquisición de 
otras competencias" (Zúñiga Lobato, 2016, p. 201). La propuesta de Zúñiga Lobato (2016), Janssen y Stoyanov (2012) y Ferrari (2013) se conforma por doce dimensiones, que se presentan en la figura 1.

Figura 1. Dimensiones de la competencia digital asumidas en la investigación.

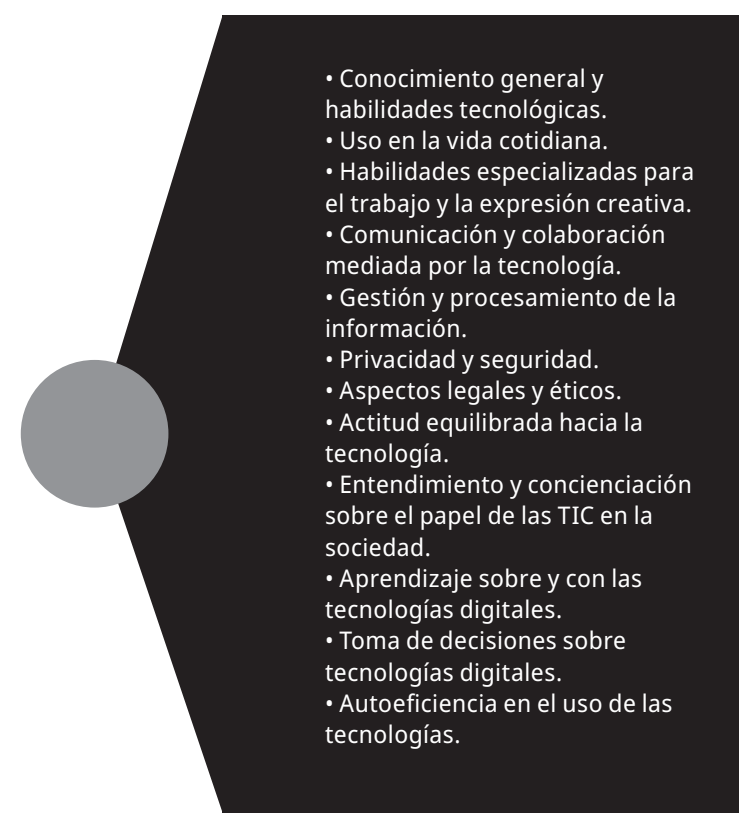

Fuente: adaptado de Zúñiga Lobato (2016), Janssen y Stoyanov (2012) y Ferrari (2013).

Además de los trabajos de la Comisión Europea ya revisados (Janssen y Stoyanov, 2012; Ferrari, 2013), recientemente se han realizado investigaciones para medir las competencias en estudiantes universitarios, a través del empleo de diversas metodologías. En el proceso de esta revisión se encontraron algunas investigaciones, cuyo objeto fueron los estudiantes de posgrado (Mortis Lozoya, Valdés Cuervo, Angulo Armenta, García López y Cuevas Salazar, 2013; Veytia, 2013; Carrasco Lozano, Sánchez Olavarría y Carro Olvera, 2015; Røkenes y Krumsvik, 2016) y de pregrado (García Sánchez, 2015; Zúñiga Lobato, 2016; Hernández Morales, Amaya Espinosa, Rodríguez Duque, Gutiérrez Barrera y Suárez Casas, 2016; Guzmán Simón, García Jiménez y López Cobo, 2017; Álvarez Flores, Núñez Gómez y Rodríguez Crespo, 2017).
Sonia Mortis y otros investigadores (2013), en un estudio de autoevaluación dirigido a 194 docentes que estudiaban un posgrado en educación, encontraron que la percepción del nivel de competencias digitales se relaciona de manera negativa con la edad y de manera positiva con estudiar un posgrado, con el acceso a la tecnología y con la cantidad de cursos que se han recibido. Concluyeron también que es necesario mejorar las competencias didáctico-metodológicas en los docentes. Por su parte, María Guadalupe Veytia (2013) hizo un estudio con 15 alumnos de posgrado en educación, mediante un cuestionario de tipo cuantitativo denominado Cobadi (2013); se encontró, gracias a este, que algunas herramientas son poco utilizadas y que es muy importante fortalecer el aprendizaje permanente, autónomo y crítico de los alumnos para reforzar las competencias digitales. María Elza Carrasco Lozano y sus colaboradores (2015) también analizaron a 15 estudiantes de posgrado en educación, por medio de un cuestionario de tipo cuantitativo, y encontraron que el nivel de competencias digitales es medio. Sin embargo, en el uso de herramientas más avanzadas, los niveles son bajos. En su estudio buscaron identificar si había una diferencia significativa entre la población hombre y mujer en cuanto al nivel de competencia digital, pero no hallaron evidencia de esto. Fredrik Røkenes y Rune Johan Krumsvik (2016), a través del método de caso, estudiaron a profesores de posgrado noruegos que tomaban un curso de actualización. En su investigación encontraron resultados variados que adjudicaron a "factores tales como modelar, andamiar experiencias de aprendizaje, vincular teoría y práctica, reflexión, acceso a recursos y apoyo, prácticas de evaluación innovadoras y aprendizaje colaborativo" (p. 1). Los estudios anteriores tuvieron en común el uso de muestras no probabilísticas y de tamaño pequeño.

Otro grupo de investigaciones realizado con estudiantes de educación superior, pero en este caso de pregrado, mostró lo siguiente: Soraya García-Sánchez (2015) trabajó sobre una muestra de 220 estudiantes de lengua inglesa de modalidad "a distancia”, enfocada en el $u$-learning, a través de un cuestionario, y encontró que los sujetos de estudio 
habían "demostrado con éxito la superación de competencias comunicativas y digitales" (p. 84). Zúñiga Lobato (2016) utilizó el mismo cuestionario de la investigación anterior y reveló que los 120 estudiantes de licenciatura mexicanos encuestados tenían un nivel general de competencia digital básica intermedio-alto y en la competencia digital trasversal un nivel intermedio-bajo. Olga Camila Hernández Morales y su grupo de investigación (2016) utilizaron un método de caso mixto para investigación cualitativa, con el fin de describir lo que denominan competencias tecnológicas en nativos digitales, mediante una encuesta en línea, que sirvió como instrumento de recolección de datos y contenía preguntas abiertas que luego fueron cuantificadas mediante escalas. Hicieron algunos hallazgos significativos: encontraron, por ejemplo, que los 67 nativos digitales colombianos que fueron sujetos de la investigación utilizan las herramientas tecnológicas de manera intensiva para fines comunicativos, por lo que las "instituciones educativas deben implementar prácticas de enseñanza y aprendizaje, apoyadas por fuentes académicas, interactivas e interesantes" (Hernández Morales, 2016, p. 101). Fernando Guzmán Simón, Eduardo García-Jiménez e Isabel López-Cobo (2017) realizaron un estudio con una muestra de 786 estudiantes españoles de educación y, mediante el uso de cuestionarios, encontraron una brecha considerable entre la competencia digital desarrollada en entornos de aprendizaje informal, así como la escasez de las prácticas de albetización en entornos formales, tales como la universidad. Érika Álvarez Flores, Patricia Núñez Gómez y Carlos Rodríguez Crespo (2017) se basaron en las dimensiones establecidas por la Comisión Europea (Ferrari, 2013) y compararon la adquisición de competencias digitales de estudiantes mexicanos con la de los españoles, pero no encontraron diferencias significativas entre ambas poblaciones.

Finalmente, para cerrar este apartado, se revisará el concepto denomidado blended learning o b-learning. Lilián de Arco Paternina, Hugo Barrios Barceló y Ginna Parra Ortega (2017) lo definen como la combinación de las tecnologías físicas de uso presencial y sincrónicas con aquellas de tipo virtual, de uso no presencial y asincrónicas. Uno de los aspectos positivos a considerar en el uso del b-learning está asociado con los evidentes resultados favorables en el profesorado (González-Yebra, Aguilar, Aguilar y Matheu, 2018). Esta percepción puede variar, ya sea que se trate de nativos o de inmigrantes digitales. Desde la visión de Ramón Villacrés Pástor, Wiliam Zea Pizarro, Víctor Vaccaro Macías y Elsy Avalos Moreno (2017), el $b$-learning requiere de manera indispensable para su implementación: una sinergia entre las TIC y lo pedagógico, relación denominada e-learning; un modelo educativo diseñado particularmente para este propósito, y profesionales de la educación experimentados y competentes en el despliegue de estas estrategias educativas.

Desde el punto de vista de la gestión educativa, el b-learning puede ser abordado desde una perspectiva que privilegia la dimensión pedagógica, es decir, el proceso de aprendizaje y las actividades formativas. Por otra parte, está la perpectiva centrada en el estudiante, que hace énfasis en la flexibilidad, los sistemas de comunicación y los escenarios tecnológicos (Salinas Ibáñez, De Benito Crosetti, Pérez Garcies y Gisbert Cervera, 2018), es decir, en los ambientes virtuales de aprendizaje. Carolina Arévalo Rodríguez (2018) llama "aprendizaje híbrido" al b-learning y destaca cómo las TIC se han convertido en su herramienta fundamental para los modelos educativos de la educación superior en México y cómo alrededor del mundo estas se han convertido en una tendencia; en el caso de las universidades privadas, por ejemplo, han aportado a un modelo de negocio.

En México, el b-learning, dada su naturaleza, se ha adaptado como una modalidad educativa y "mixta". Se caracteriza por combinar estrategias, recursos y métodos, teniendo en cuenta "las características de la población que atiende, la naturaleza del modelo académico, así como los recursos y condiciones de la instituación educativa" (DOF, 2008, p. 6). Una de sus características fundamentales es que al menos el $40 \%$ de las actividades de aprendizaje se llevan a cabo bajo el acompañamiento del docente, lo cual influye en la distancia de las modalidades presenciales (al menos un $80 \%$ ) y de la virtual (al menos un $20 \%$ ). Se asume que el resto del tiempo se destina a actividades en 
las que el alumno trabaja de manera independiente. Es por ello que los Sistemas de Administración del Aprendizaje (LMS, según sus siglas en inglés) resultan muy pertinentes para estos propósitos, porque orientan, acompañan y le dan seguimiento al estudiante durante el trabajo independiente (Villacrés Pástor, Zea Pizarro, Vaccaro Macías y Avalos Moreno, 2017). Cabe aclarar que la legislación mexicana no contempla que el uso de las TiC (e-learning) sean un requisito para la educación mixta. No obstante, de acuerdo a lo ya mencionado, esta es una práctica generalizada en la educación superior de México en los últimos años.

\section{Metodología}

En esta investigación se adoptó el concepto de competencia digital como:

el conjunto de conocimientos, destrezas, actitudes, habilidades, estrategias y conciencia que se requieren al usar las TIC y los medios digitales para realizar tareas; resolver problemas; comunicar; administrar información; colaborar; crear y compartir contenido; y construir conocimiento de manera efectiva, eficiente, apropiada, crítica, creativa, autónoma, flexible, ética, reflexiva para el trabajo, el ocio, la participación, el aprendizaje, la socialización, el consumo y el empoderamiento (Ferrari, 2012, p. 30).

La presente investigación es de enfoque cuantitativo; se creó una definición y operacionalización de la variable competencia digital y se midieron sus dimensiones y, a su vez, los indicadores. La medición se hizo en una sola ocasión, por lo que fue de tipo transversal. El alcance es descriptivo-correlacional, ya que se caracteriza a la población en sus aspectos sociodemográficos y en cuanto al nivel de dominio de la competencia digital. Además, se buscó si existen relaciones estadísticamente significativas entre las variables sociodemográficas y las dimensiones de la variable competencia digital. Es un modelo no experimental, dado que las hipótesis se probaron mediante técnicas estadísticas y no a través del control de variables.

El objetivo de la presente investigación es caracterizar el nivel de competencia digital en los estudiantes de doctorado y las variables sociodemográficas que pueden influir en este.

Se consideraron las siguientes hipótesis de investigación:

Hipótesis 1: los estudiantes de doctorado tienen un alto nivel de dominio de la competencia digital.

Hipótesis 2: existe una relación estadísticamente significativa entre el dominio de la competencia digital en los estudiantes de doctorado y la modalidad que curse el encuestado.

Hipótesis 3: existe una relación estadísticamente significativa entre el dominio de la competencia digital de los estudiantes de doctorado y el género del encuestado.

La población elegida está conformada por estudiantes de doctorado; en este caso se tuvo acceso a tres programas distintos de dos instituciones. Se seleccionó una muestra de tipo censal, dado que la población total disponible no fue de gran tamaño (en total 77 estudiantes: $56 \%$ mujeres y $44 \%$ hombres). Los tres programas educativos fueron: Educación en una Universidad de San Luis Potosí (modalidad mixta): $20 \%$; Administración en una Universidad de San Luis Potosí (modalidad mixta): 30 \%; Socioformación en la Universidad de Morelos (modalidad a distancia): $50 \%$. En cuanto al año que cursan, el $70 \%$ de los estudiantes se encuentra en primer año; $24,7 \%$ en segundo año, y el resto, $5,3 \%$, en tercer año y más adelante.

Se utilizó el "Cuestionario de competencias digitales", versión en español, de Zúñiga Lobato (2016, pp. 235-252), adaptación del instrumento propuesto por Janssen y Stonayov (2012, pp. 34-51), que mide la competencia digital. El cuestionario final cuenta con ochenta y tres preguntas cerradas con escalas de Likert, que miden la percepción del nivel de dominio de las dimensiones de la competencia digital. Dicho instrumento fue validado por los autores originales mediante el método Delphi, a través de dos rondas y doscientos cuatro expertos.

En este estudio, para garantizar la confiabilidad interna del instrumento, se aplicó la prueba estadística Alpha de Cronbach, y se obtuvieron los resultados que se muestran a continuación, en la tabla 1. 
Tabla 1. Resultados del análisis del Alpha de Cronbach en el instrumento

\begin{tabular}{|c|c|c|c|c|}
\hline Dimensión & $\begin{array}{l}\text { Total de } \\
\text { ítems } \\
\text { iniciales }\end{array}$ & $\begin{array}{l}\text { Alfa } \\
\text { inicial }\end{array}$ & $\begin{array}{l}\text { Total } \\
\text { de } \\
\text { ítems } \\
\text { finales }\end{array}$ & $\begin{array}{l}\text { Alfa } \\
\text { final }\end{array}$ \\
\hline $\begin{array}{l}\text { Conocimiento } \\
\text { general y } \\
\text { habilidades } \\
\text { tecnológicas }\end{array}$ & 7 & 0,831 & 7 & 0,831 \\
\hline $\begin{array}{l}\text { Uso en la vida } \\
\text { cotidiana }\end{array}$ & 10 & 0,865 & 10 & 0,865 \\
\hline $\begin{array}{l}\text { Habilidades } \\
\text { especializadas } \\
\text { para el trabajo y la } \\
\text { expresión creativa }\end{array}$ & 8 & 0,765 & 7 & 0,779 \\
\hline $\begin{array}{l}\text { Comunicación } \\
\text { y colaboración } \\
\text { mediada por la } \\
\text { tecnología }\end{array}$ & 10 & 0,9 & 10 & 0,9 \\
\hline $\begin{array}{l}\text { Gestión y } \\
\text { procesamiento de } \\
\text { la información }\end{array}$ & 10 & 0,892 & 10 & 0,892 \\
\hline $\begin{array}{l}\text { Privacidad y } \\
\text { seguridad }\end{array}$ & 5 & 0,777 & 4 & 0,809 \\
\hline $\begin{array}{l}\text { Aspectos legales y } \\
\text { éticos }\end{array}$ & 5 & 0,749 & 5 & 0,749 \\
\hline $\begin{array}{l}\text { Actitud equilibrada } \\
\text { hacia la tecnología }\end{array}$ & 5 & 0,027 & 0 & NA \\
\hline $\begin{array}{l}\text { Entendimiento } \\
\text { y concienciación } \\
\text { sobre el papel } \\
\text { de las TIC en la } \\
\text { sociedad }\end{array}$ & 5 & 0,799 & 4 & 0,808 \\
\hline $\begin{array}{l}\text { Aprendizaje sobre y } \\
\text { con las tecnologías } \\
\text { digitales }\end{array}$ & 5 & 0,876 & 5 & 0,876 \\
\hline $\begin{array}{l}\text { Toma de decisiones } \\
\text { sobre tecnologías } \\
\text { digitales }\end{array}$ & 5 & 0,809 & 5 & 0,809 \\
\hline $\begin{array}{l}\text { Autoeficiencia } \\
\text { en el uso de las } \\
\text { tecnologías }\end{array}$ & 5 & 0,852 & 5 & 0,852 \\
\hline
\end{tabular}

Como se observa en la tabla 1, la mayoría de las dimensiones alcanzaron niveles apropiados de consistencia interna para ser utilizadas. En aquellos casos en los que el valor era bajo, se eliminaron los ítems con baja correlación, salvo en el caso de la dimensión "Actitud equilibrada hacia la tecnología”, que mostró ser muy poco confiable, por lo cual fue eliminada del análisis. El caso del análisis de validez se apoyó en el análisis factorial exploratorio por el método de componentes principales. Se hizo un análisis agregando dimensión por dimensión. Al final, se dedujo que algunas de estas dimensiones no resultaron óptimas para aquel. De las doce dimensiones se mantuvieron ocho, en parte por la gran cantidad de ítems (setenta y dos en la versión corregida) y por el número de instrumentos aplicados (77 sujetos). En cuanto a la medición, el valor en la prueba Kayser Meyer Olkin (кмо) fue 0,737 , lo que indica un nivel mediano de pertinencia de uso de esta prueba. La prueba de esfericidad de Bartlett, con una significación del 0,0, mostró que no se trata de una matriz de identidad, por lo cual es válido el uso del análisis factorial (ver tabla 2).

Tabla 2. Análisis de dimensiones que conforman el instrumento

\begin{tabular}{ll}
\hline Número de ítems iniciales & Número de ítems finales \\
\hline 75 & 48 \\
\hline Dimensiones iniciales & Dimensiones finales \\
\hline $\begin{array}{l}\text { Conocimiento general y } \\
\text { habilidades tecnológicas }\end{array}$ & \\
\hline $\begin{array}{l}\text { Uso en la vida cotidiana } \\
\text { Habilidades especializadas } \\
\text { para el trabajo y la expresión } \\
\text { creativa }\end{array}$ & $\begin{array}{l}\text { Habilidades especializadas } \\
\text { para el trabajo y la expresión } \\
\text { creativa }\end{array}$ \\
\hline $\begin{array}{l}\text { Comunicación y colaboración } \\
\text { mediada por tecnología }\end{array}$ & \\
\hline $\begin{array}{l}\text { Gestión y procesamiento de la } \\
\text { información }\end{array}$ & $\begin{array}{l}\text { Gestión y procesamiento de } \\
\text { la información }\end{array}$ \\
\hline $\begin{array}{l}\text { Privacidad y seguridad } \\
\text { Aspectos legales y éticos }\end{array}$ & $\begin{array}{l}\text { Privacidad y seguridad } \\
\text { tecnologías digitales }\end{array}$ \\
\hline $\begin{array}{l}\text { Actitud equilibrada hacia la } \\
\text { tecnología }\end{array}$ & $\begin{array}{l}\text { Aprendos legales y éticos } \\
\text { Entendimiento y } \\
\text { de las TIC en la sociedad }\end{array}$ \\
\hline $\begin{array}{l}\text { Aprendizaje sobre y con las digitales } \\
\text { concienciación sobre el papel } \\
\text { de las TIC en la sociedad }\end{array}$ \\
\hline
\end{tabular}


Toma de decisiones sobre las tecnologías digitales

Toma de decisiones sobre las tecnologías digitales

Autoeficiencia en el uso de las tecnologías

Autoeficiencia en el uso de las tecnologías

Se utilizó la rotación or togonal varimax y, como se puede observar en el gráfico de sedimentación, hay cinco notorios componentes principales (ver figura 2) cuando se extraen ocho de estos. La convergencia con el número de dimensiones se observa en la distribución de la matriz de componentes rotados (ver tabla 3). En este nivel se puede relativamente acreditar la validez del instrumento con las dimensiones ajustadas. Sin embargo, otras investigaciones deberían utilizar muestras más grandes (al menos 450 sujetos) para realizar nuevamente las pruebas de consistencia interna y validez.

Figura 2. Gráfica de sedimentación de componentes principales.

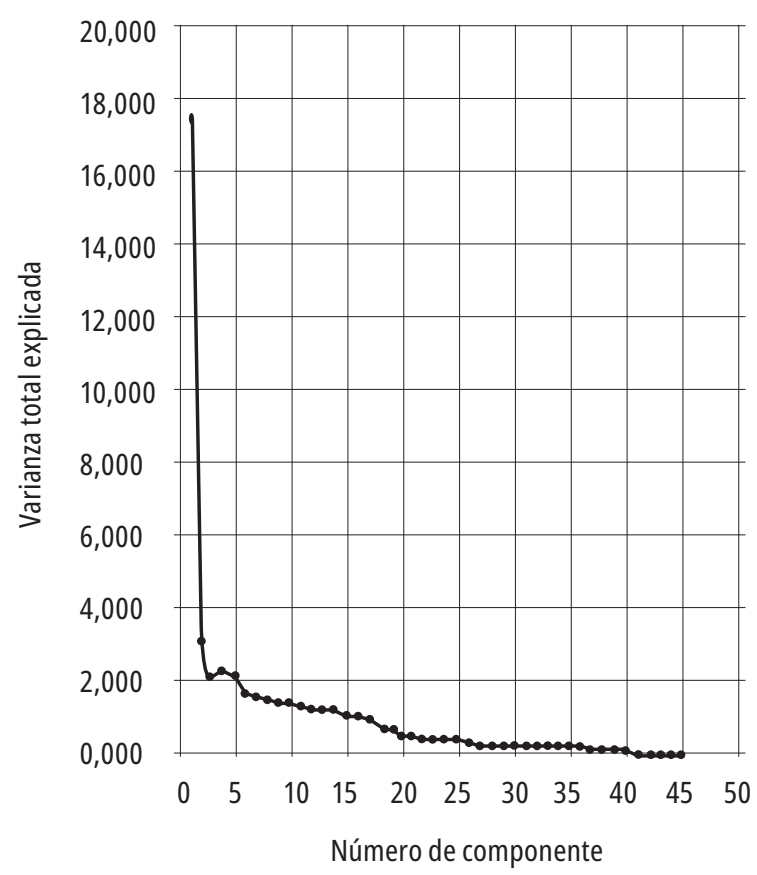

Fuente: elaboración propia.

En la tabla 3 se pueden verifican los agrupamientos entre indicadores y dimensiones y las correlaciones que guardan dichos cruces una vez aplicada la rotación ortogonal varimax.

Dado que la consistencia interna y la validez del constructo fueron analizados mediante métodos cuantitativos (estadísticos), existen contrastes en cuanto al número de dimensiones validadas, si se compara con el caso de Jannsen y Stonayov (2012), que utilizó un procedimiento cualitativo (método Delphi). Otra experiencia para validar un cuestionario que mide la competencia digital lo encontramos en el trabajo de Santiago Mengual Andrés, Rosabel Roig Vila y Josefa Eugenia Blasco-Mira (2016), quienes validaron mediante el método Delphi un cuestionario de cinco dimensiones y cincuenta y siete ítems a través de tres rondas $y$, así, lograron validar íntegramente su instrumento. El estudio informa los resultados de consistencia interna mediante un alpha de Cronbach global de 0,962 y la estabilidad entre las respuestas de los expertos, mediante el uso de la prueba de suma de rangos de Wilcoxon.

Una posible razón por la que, en este trabajo, las pruebas estadísticas realizadas no permitieron validar todas las dimensiones e ítems del cuestionario es el tamaño de la muestra utilizada en la investigación, que alcanzó a setenta y siete sujetos. También puede deberse a problemas con la adaptación al español del instrumento y a que las escalas tipo Likert, aunque siguieron siendo de cuatro niveles como en la versión original, no fueron consistentes en su tipo de escala -"mucho", "algo", "poco" o "nada", que denotan frecuencia-, sino que fueron variadas de acuerdo al criterio del investigador -"sí, y lo sabría explicar", "sí", "sí, pero con ayuda", "no", que denotan "capacidad operacional o habilidad" (Zúñiga Lobato, 2016, p. 151)-. A continuación, se presentan los principales hallazgos y la interpretación de estos, a la luz de los conceptos teóricos que ya han sido desarrollados.

\section{Resultados y discusión}

Una vez realizada la comprobación de consistencia y validez interna se presenta, a continuación, el análisis de las dimensiones de competencia digital. 
Tabla 3.Matriz de componentes rotados y correlaciones

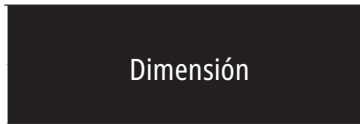

Habilidades especializadas para el trabajo y la expresión creativa

Habilidades especializadas para el trabajo y la expresión creativa

Habilidades especializadas para el trabajo y la expresión creativa
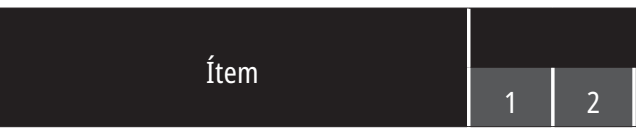

3

Componente

Sé lo que es un mapa mental, un diagrama, un mapa conceptual, etc., y puedo crearlos en una computadora.

Sé crear posters, trípticos, volantes, entre otros, utilizando herramientas digitales.

.627

Soy capaz de editar un video (recortando partes sobrantes, agregando videos, entre otros) e insertar una pista de audio como fondo.

Habilidades especializadas para el trabajo y la expresión creativa

Conozco y sé cómo utilizar un software especializado para la creación de gráficos, imágenes o diagramas.

.442 .578

Habilidades especializadas para el trabajo y la expresión creativa Puedo aprender cosas nuevas y de manera autodidacta, a través de tutoriales disponibles en internet.

Habilidades especializadas para el trabajo y la expresión creativa

Sé cómo entrar a mi página personal de la universidad para consultar calificaciones, horarios, pagos, etc.

Habilidades especializadas para el trabajo y la expresión creativa

Utilizo sistemas de almacenamiento en la nube para compartir contenido con compañeros, profesores 0 colaboradores.

Gestión y procesamiento de la información

Puedo crear cuadros comparativos, esquemas, resúmenes, entre otros, sobre un tópico, a partir de datos 0 información proveniente de diferentes fuentes.

Gestión y procesamiento de la información

Soy capaz de comparar y contrastar información de diferentes fuentes.

Gestión y procesamiento de la Para realizar trabajos de investigación información y tareas, consulto varias fuentes de información con el fin de unificarlas .753 luego en un documento.

Gestión y procesamiento de la Sigo pautas, normas o reglas para información saber si la información que encuentro en internet es falsa o verdadera.

Gestión y procesamiento de la información

Conozco bases de datos o buscadores especializados para obtener fuentes formales de información (artículos indexados, actas de congresos, revistas indexadas, tesauros, entre otros).

Puedo averiguar información específica en internet (efectos secundarios de un medicamento, contenido nutricional de un alimento, una receta en específico). 

\begin{tabular}{l} 
Gestión y procesamiento de la \\
información \\
\hline Gestión y procesamiento de la \\
información
\end{tabular}

Gestión y procesamiento de la
información

Gestión y procesamiento de la
información

Gestión y procesamiento de la
información

Utilizo marcadores o favoritos y los

administro organizadamente, creando

carpetas, asignando etiquetas y

valorándolas según su importancia.

Utilizo marcadores o menú de favoritos

para localizar páginas útiles o de mi interés.
.713

Consulto opiniones en línea y reseñas

sobre bienes de consumo, para

averiguar si vale la pena adquirir un

producto o servicio.

Para realizar un trabajo de

investigación o proyecto, no

solo consulto textos, sino videos

documentales, grabaciones, podcasts,

imágenes, entre otros, para integrar un

trabajo final.

Toma de decisiones sobre tecnologías digitales

Puedo identificar si un recurso digital

(imagen, video, documento) es relevante 0 de interés y me podría ser

útil en el futuro, aun si no lo necesito en este momento.

\begin{tabular}{|c|c|c|}
\hline $\begin{array}{l}\text { Toma de decisiones sobre } \\
\text { tecnologías digitales }\end{array}$ & $\begin{array}{l}\text { Conozco medidas para protegerme de } \\
\text { ataques de robo de identidad. }\end{array}$ & .566 \\
\hline Privacidad y seguridad & $\begin{array}{l}\text { Sé cómo identificar cuando un correo } \\
\text { electrónico (o cualquier otro tipo } \\
\text { de mensaje) conlleva una acción } \\
\text { ilegal o presenta una situación de } \\
\text { riesgo (malware, estafa, robo de } \\
\text { credenciales), aun cuando pareciera } \\
\text { provenir de una fuente confiable } \\
\text { (phishing). }\end{array}$ & .814 \\
\hline Privacidad y seguridad & $\begin{array}{l}\text { Sé cómo establecer configuraciones } \\
\text { rigurosas de privacidad en las redes } \\
\text { sociales. }\end{array}$ & .762 \\
\hline Privacidad y seguridad & $\begin{array}{l}\text { Estoy enterado de que muchos } \\
\text { servicios interactivos utilizan } \\
\text { información sobre mi historial y } \\
\text { hábitos de navegación para fines } \\
\text { publicitarios y seguimiento de usuario. } \\
\text { Sé cómo configurar el navegador para } \\
\text { evitarlo. }\end{array}$ & .753 \\
\hline Aspectos legales y éticos & $\begin{array}{l}\text { Conozco las diferentes licencias de } \\
\text { reproducción de contenido como: } \\
\text { Creative Commons, Licencia de } \\
\text { reutilización con modificaciones, } \\
\text { Licencia de reutilización no comercial, } \\
\text { entre otras. }\end{array}$ & .797 \\
\hline Aspectos legales y éticos & $\begin{array}{l}\text { Conozco los diferentes tipos de licencia } \\
\text { de software: código abierto, software } \\
\text { libre, licencia de usuario final, entre } \\
\text { otros. }\end{array}$ & .749 \\
\hline
\end{tabular}




\begin{tabular}{|c|c|c|c|c|c|c|c|}
\hline Aspectos legales y éticos & $\begin{array}{l}\text { Reconozco en qué momento y a } \\
\text { través de cuáles herramientas estoy } \\
\text { adquiriendo contenidos o software sin } \\
\text { pagar derechos de autor. }\end{array}$ & & & & .687 & & \\
\hline Aspectos legales y éticos & $\begin{array}{l}\text { Sé por qué es inadecuado escribir todo } \\
\text { un mensaje en mayúsculas, según las } \\
\text { normas de comportamiento general en } \\
\text { internet (Netiqueta). }\end{array}$ & & & & & .684 & \\
\hline Aspectos legales y éticos & $\begin{array}{l}\text { Conozco el tipo de licencia de uso, } \\
\text { bajo el cual quedan sujetas mis } \\
\text { publicaciones en internet y redes } \\
\text { sociales. }\end{array}$ & & & & & .456 & \\
\hline Aspectos legales y éticos & $\begin{array}{l}\text { Conozco cómo funciona el software de } \\
\text { aprendizaje en línea de la universidad y } \\
\text { puedo llevar cursos en línea. }\end{array}$ & & & & & & .697 \\
\hline $\begin{array}{l}\text { Entendimiento y } \\
\text { concienciación sobre el papel } \\
\text { de las TIC en la } \\
\text { sociedad }\end{array}$ & $\begin{array}{l}\text { Soy consciente del origen de las } \\
\text { Tecnologías de la Información, } \\
\text { de quién las desarrolla y con qué } \\
\text { propósitos. }\end{array}$ & & & .771 & & & \\
\hline $\begin{array}{l}\text { Entendimiento y } \\
\text { concienciación sobre el papel } \\
\text { de las TIC en la } \\
\text { sociedad }\end{array}$ & $\begin{array}{l}\text { Me mantengo informado sobre las } \\
\text { nuevas tendencias tecnológicas } \\
\text { (drones, impresoras 3D, realidad } \\
\text { virtual, cómputo ubicuo, etc.). }\end{array}$ & & & .727 & & & \\
\hline $\begin{array}{l}\text { Entendimiento y } \\
\text { concienciación sobre el papel } \\
\text { de las TIC en la } \\
\text { sociedad }\end{array}$ & $\begin{array}{l}\text { Conozco los problemas ecológicos } \\
\text { relacionados con el uso de las } \\
\text { tecnologías (huella de carbono, basura } \\
\text { electrónica, consumo energético, } \\
\text { contaminación del agua). }\end{array}$ & & & .656 & & & \\
\hline $\begin{array}{l}\text { Entendimiento y } \\
\text { concienciación sobre el papel } \\
\text { de las TIC en la } \\
\text { sociedad }\end{array}$ & $\begin{array}{l}\text { Entiendo los siguientes conceptos: } \\
\text { ciudadanía digital, sociedad de } \\
\text { la información, sociedad del } \\
\text { conocimiento, brecha digital. }\end{array}$ & .483 & & .600 & & & \\
\hline $\begin{array}{l}\text { Aprendizaje sobre y con las } \\
\text { tecnologías digitales }\end{array}$ & $\begin{array}{l}\text { Puedo aprender a utilizar aplicaciones } \\
\text { y herramientas tecnológicas mientras } \\
\text { las pruebo, sin necesidad de un } \\
\text { instructivo. }\end{array}$ & & .645 & & & & \\
\hline $\begin{array}{l}\text { Aprendizaje sobre y con las } \\
\text { tecnologías digitales }\end{array}$ & $\begin{array}{l}\text { Soy capaz de crear un tutorial de una } \\
\text { actividad que domino y publicarlo en } \\
\text { internet. }\end{array}$ & & .555 & & & & \\
\hline $\begin{array}{l}\text { Aprendizaje sobre y con las } \\
\text { tecnologías digitales }\end{array}$ & $\begin{array}{l}\text { Conozco cursos abiertos y recursos } \\
\text { disponibles en internet para estudiar } \\
\text { tópicos de mi interés, sean académicos } \\
\text { o no. }\end{array}$ & & .539 & & & & \\
\hline $\begin{array}{l}\text { Aprendizaje sobre y con las } \\
\text { tecnologías digitales }\end{array}$ & $\begin{array}{l}\text { Instalo actualizaciones en mis } \\
\text { dispositivos tecnológicos y en mi } \\
\text { paquetería de Office y sé adaptarme } \\
\text { fácilmente a los cambios. }\end{array}$ & & .520 & & & & \\
\hline $\begin{array}{l}\text { Toma de decisiones sobre las } \\
\text { tecnologías digitales }\end{array}$ & $\begin{array}{l}\text { Conozco las tecnologías más } \\
\text { apropiadas y comunes que son } \\
\text { utilizadas en mi área profesional y } \\
\text { otras áreas. }\end{array}$ & .412 & .412 & & & & \\
\hline $\begin{array}{l}\text { Toma de decisiones sobre las } \\
\text { tecnologías digitales }\end{array}$ & $\begin{array}{l}\text { Elijo las tecnologías más apropiadas de } \\
\text { acuerdo con la tarea que debo realizar. }\end{array}$ & & & .613 & & & \\
\hline
\end{tabular}




\begin{tabular}{|c|c|c|c|}
\hline $\begin{array}{l}\text { Toma de decisiones sobre las } \\
\text { tecnologías digitales }\end{array}$ & $\begin{array}{l}\text { Sé cuál es el límite de capacidad para } \\
\text { enviar archivos adjuntos a través de } \\
\text { un correo electrónico y conozco vías } \\
\text { alternas para compartirlo cuando dicho } \\
\text { límite es superado. }\end{array}$ & & \\
\hline $\begin{array}{l}\text { Toma de decisiones sobre las } \\
\text { tecnologías digitales }\end{array}$ & $\begin{array}{l}\text { Utilizo recursos y medios digitales, } \\
\text { si fallan: se pierde la conexión } \\
\text { de internet, se descompone mi } \\
\text { computadora, se va la luz, entre otros. }\end{array}$ & & \\
\hline $\begin{array}{l}\text { Autoeficiencia en el uso de las } \\
\text { tecnologías }\end{array}$ & $\begin{array}{l}\text { Puedo resolver problemas técnicos } \\
\text { con o sin ayuda de las herramientas de } \\
\text { soporte técnico proporcionadas por el } \\
\text { fabricante. }\end{array}$ & .677 & \\
\hline $\begin{array}{l}\text { Autoeficiencia en el uso de las } \\
\text { tecnologías }\end{array}$ & $\begin{array}{l}\text { Conozco páginas y sitios web } \\
\text { especializados en soluciones a } \\
\text { problemas técnicos u operacionales. }\end{array}$ & .607 & .425 \\
\hline $\begin{array}{l}\text { Autoeficiencia en el uso de las } \\
\text { tecnologías }\end{array}$ & $\begin{array}{l}\text { Puedo utilizar las tecnologías } \\
\text { como apoyo para alcanzar mejores } \\
\text { resultados en un menor tiempo en mis } \\
\text { tareas o actividades. }\end{array}$ & .487 & .400 \\
\hline $\begin{array}{l}\text { Autoeficiencia en el uso de las } \\
\text { tecnologías }\end{array}$ & $\begin{array}{l}\text { Personalizo mi computadora o } \\
\text { dispositivo para que me sea más } \\
\text { práctico utilizarlos (colocación de } \\
\text { accesos directos, apariencia de los } \\
\text { íconos). }\end{array}$ & .462 & \\
\hline $\begin{array}{l}\text { Autoeficiencia en el uso de las } \\
\text { tecnologías }\end{array}$ & $\begin{array}{l}\text { Desarrollo técnicas personales para } \\
\text { utilizar las herramientas digitales } \\
\text { eficientemente (uso de atajos de } \\
\text { teclado, copia y pega de instrucciones, } \\
\text { entre otros). }\end{array}$ & .442 & \\
\hline
\end{tabular}

Este dominio se refiere a la capacidad del sujeto para expresar su creatividad y mejorar su actuación profesional mediante el uso de las TIC (Janssen y Stoyanov, 2012, p. 17). Se encontró que más de la mitad de los participantes tenía un nivel alto. Sin embargo, llama la atención que el porcentaje de este nivel no sea mayor, dado el supuesto grado de habilitación de los estudiantes que estudian el doctorado y teniendo en cuenta, además, que todos se encuentran en modalidades b-learning o estudiando a distancia (ver figura 3 ).

Este dominio se refiere al uso de la tecnología para mejorar las habilidades de obtener, organizar, analizar y juzgar la relevancia y los propósitos de la información digital (Janssen y Stoyanov, 2012). Llama la atención la aparición de sujetos que tienen un nivel bajo e incluso nulo. Los resultados mostraron que las personas de mayor edad tienen
Figura 3. Nivel de dominio de las habilidades especializadas para el trabajo y la expresión creativa.

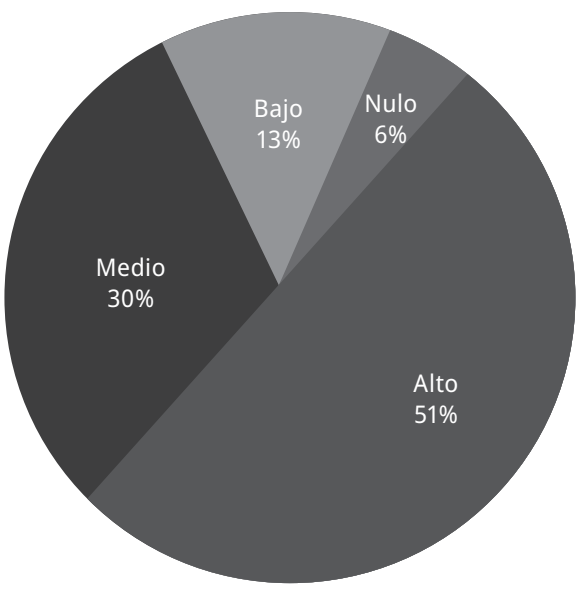

Fuente: elaboración propia. 
mayor dificultad en esta dimensión. Un nivel de habilitación bajo en este dominio por parte de los participantes mayores da una idea de las dificultades que los inmigrantes digitales tienen con el uso de las TIC (ver figura 4).

Figura 4. Nivel de dominio de las habilidades en gestión y procesamiento de información.

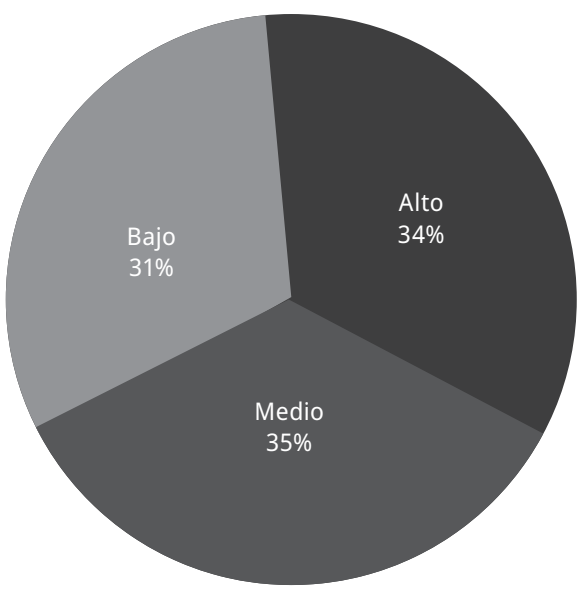

Fuente: elaboración propia.

Este dominio se refiere a la capacidad para proteger los datos personales, así como para tomar las medidas de seguridad apropiadas (Janssen y Stoyanov, 2012). Los resultados muestran que dos terceras partes no han desarrollado adecuadamente esta dimensión de la competencia digital. Los resultados coinciden con los encontrados por Zúñiga Lobato (2016), en los que se evidencia una dispersión, pues los niveles de dominio de los sujetos se reparten casi equitativamente. Un bajo nivel en este aspecto genera amenazas a la información personal, incluso al patrimonio (ver figura 5).

El nivel de dominio de los aspectos legales y éticos se refiere a los comportamientos apropiados, en cuanto a la responsabilidad social, en los ambientes digitales, es decir, comportamientos que demuestren conciencia y conocimiento de los aspectos éticos y legales en el uso de las TIC y los contenidos digitales (Janssen y Stoyanov, 2012). Igual que en los resultados de la dimensión anterior se denota una falta de conocimiento y conciencia sobre los comportamientos adecuados a favor de la protección y el uso de la propiedad intelectual, lo cual puede llevar al individuo a cometer delitos sin tener conciencia de ello (ver figura 6).

Figura 5. Nivel de dominio de las habilidades para la privacidad y seguridad.

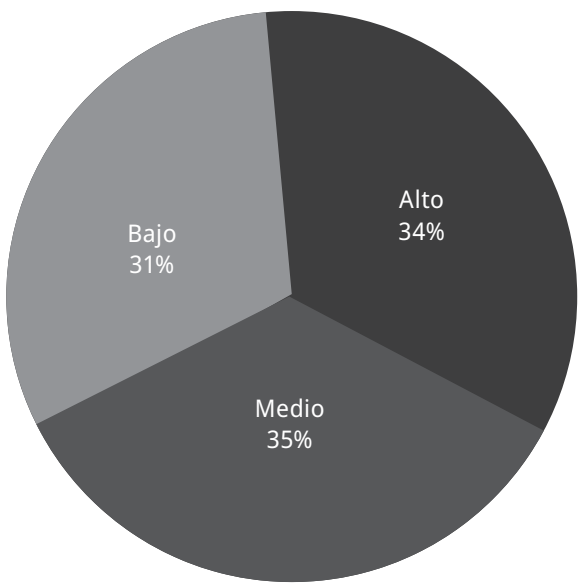

Fuente: elaboración propia.

Figura 6. Nivel de dominio de los aspectos legales y éticos.

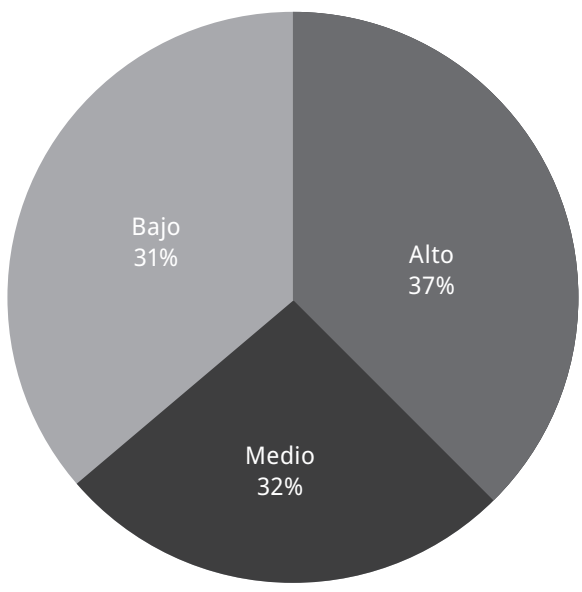

Fuente: elaboración propia.

El nivel de entendimiento y concienciación sobre el papel de las TIC en la sociedad se manifiesta en la capacidad para comprender el contexto y los roles más amplios del uso y desarrollo de las TIC (Janssen y Stoyanov, 2012, p. 17). Generalmente implica procesos metacognitivos en los que se reconoce el papel que las TIC desempeñan en la vida diaria y en las relaciones. Un nivel de conciencia 
elevado se reflejará en una actuación más responsable y equilibrada de las tecnologías, que se caracteriza por la apropiación adecuada de sus beneficios y no por el padecimiento a causa de su impacto. En la muestra llama la atención que más de una tercera parte de los participantes tiene un nivel bajo en este aspecto. Sin embargo, la media es más alta que la encontrada en los estudiantes de licenciatura (Zúñiga Lobato, 2016). (ver figura 7).

Figura 7. Nivel de entendimiento y concienciación sobre el papel de las TIC en la sociedad.

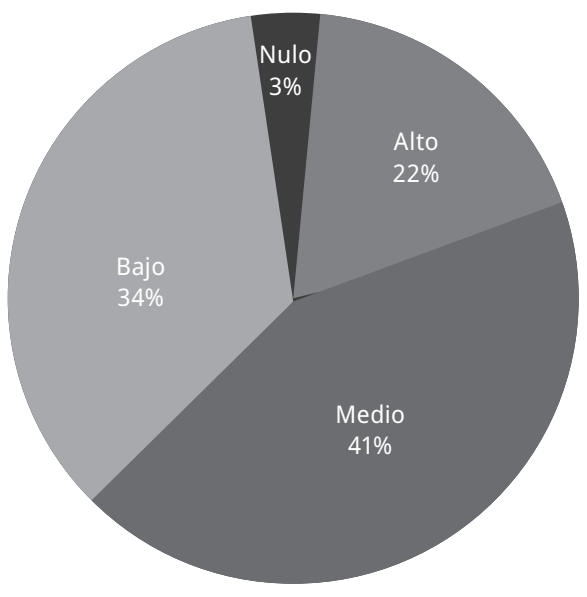

Fuente: elaboración propia.

Esta dimensión es visible cuando la persona es activa y constantemente explora las tecnologías emergentes, las integra en su entorno y las usa para su aprendizaje permanentemente (Janssen y Stoyanov, 2012, p. 17). El hecho de que más de la mitad de los participantes tenga niveles de medio a nulo, da cuenta de una debilidad en cuanto al descubrimiento e incorporación de las TIC en sus procesos de aprendizaje (ver figura 8).

Este dominio implica la conciencia de las tecnologías más importantes y más utilizadas; el individuo que tiene capacidades en aquel es capaz de elegir la tecnología más apropiada, de acuerdo con el propósito o necesidad que se le presente (Janssen y Stoyanov, 2012, p. 17). Este nivel de habilitación permite la eficacia en las tareas y en general permite al sujeto ser productivo, gracias al apoyo de las TIC. Se encontró que la mayor parte de los estudiantes tiene un nivel medio, pero se destaca que más de una tercera parte alcanza niveles altos (ver figura 9).

Figura 8. Nivel de aprendizaje sobre y con las tecnologías digitales.

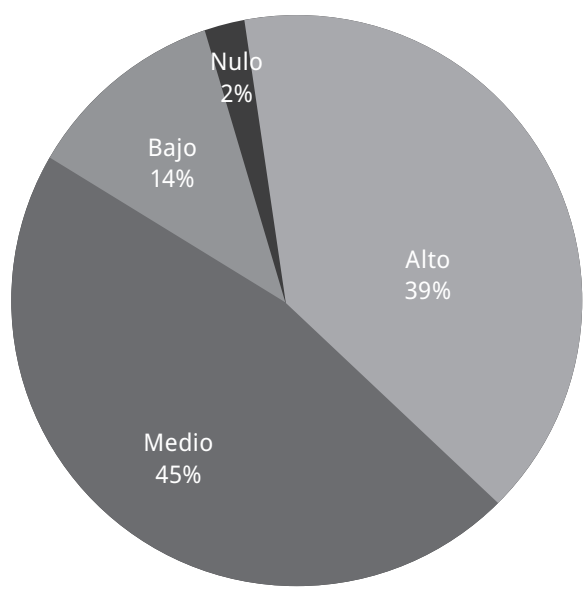

Fuente: elaboración propia.

Figura 9. Nivel de dominio para la toma de decisiones sobre las tecnologías digitales.

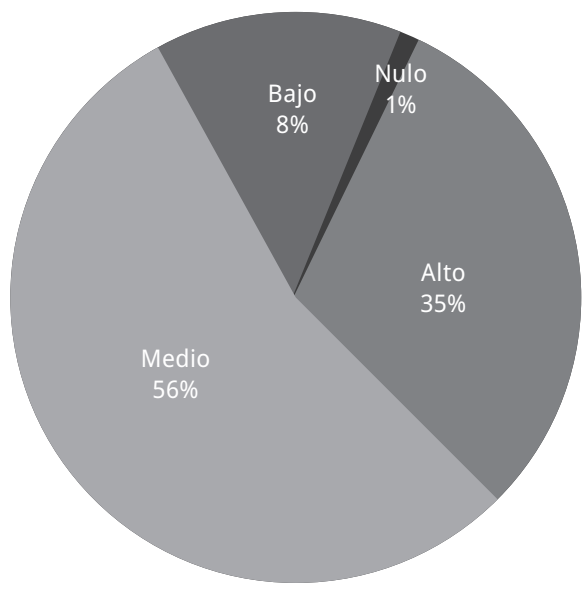

Fuente: elaboración propia.

Con un adecuado nivel de autoeficiencia en el uso de las tecnologías, el usuario se siente cómodo y es creativo utilizando los medios digitales para incrementar la eficiencia y efectividad personal y profesional (Janssen y Stoyanov, 2012, p. 17). Dos terceras partes de los encuestados no logran aprovechar y combinar las capacidades de las TIC para facilitar sus actividades. Se encontró 
que los niveles de autoeficacia nos son afectados por la variable sexo, como lo sugieren otras investigaciones. Por el contrario, con respecto a esto se encuentran coincidencias con los resultados del trabajo de Carrasco y su grupo de investigación (2015) (ver figura 10).

Figura 10. Nivel de autoeficiencia en el uso de las tecnologías.

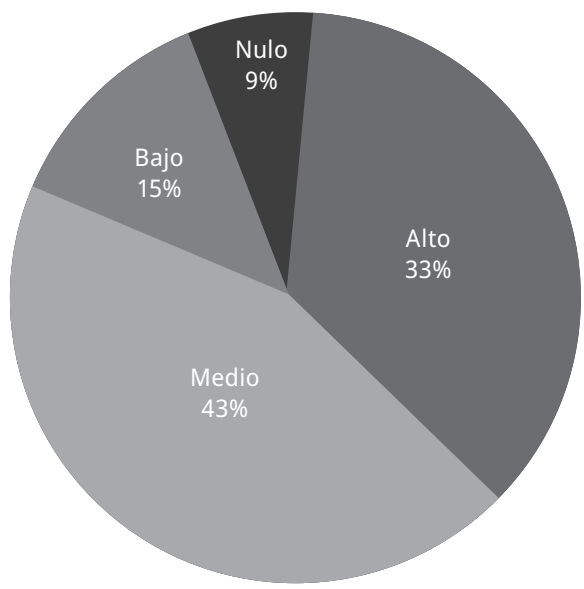

Fuente: elaboración propia.
En la figura 11 se puede observar el resumen de las dimensiones de competencia digital que fueron finalmente medidas. Dado que los rangos del instrumento van del 1 al 5, un nivel de 3 se ubicaría en la mitad de la escala. Se observa que únicamente la dimensión "Entendimiento y concienciación sobre el papel de las TIC en la sociedad" se encuentra por debajo de este nivel. Dicha dimensión tiene un carácter reflexivo y más cercano a una actitud que a una habilidad, a diferencia de las demás dimensiones que alcanzaron al menos el nivel 3. Sin embargo, todas están lejos de niveles medio altos o altos.

Se buscaron, además, relaciones estadísticamente significativas mediante el cruce de las variables cualitativas, a través de la prueba Chi-cuadrado de Pearson y de la prueba exacta de Fisher, una y otra de acuerdo con las características de los datos. Los datos relevantes fueron los siguientes:

El programa de doctorado que se cursa mostró seis relaciones estadísticamente significativas con indicadores medidos y se constituye como la variable que, de manera destacada, influye en la competencia digital. La razón que puede explicar esta influencia es que los estudiantes de la universidad con mayores niveles de competencia estudian un programa a distancia, lo cual es un requisito para

Figura 11. Media de las dimensiones de la competencia digital.

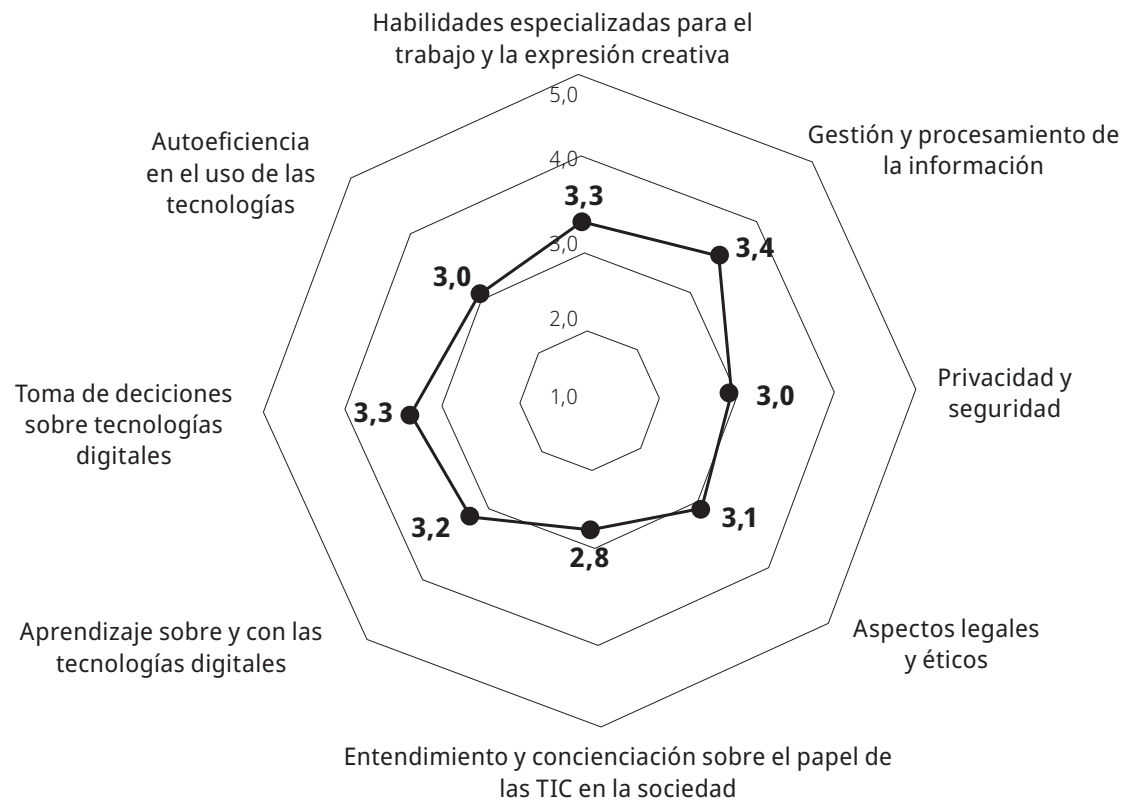

Fuente: elaboración propia. 
desenvolverse adecuadamente en el programa; en ello se diferencian de los estudiantes de la otra universidad, que estudian en la modalidad b-learning, cuyo funcionamiento incluye el uso de plataformas virtuales (en este caso Moodle), pero tiene, no obstante, un componente presencial que predomina en el proceso enseñanza-aprendizaje. No se encontró relación entre el nivel de competencias digitales y la disciplina en la que se estudia el programa de doctorado, en este caso Administración y Educación. La variable sexo o género presentó tres relaciones estadísticamente significativas con dimensiones de la competencia digital y el semestre que se cursa dos relaciones estadísticamente significativas. Sin embargo, no se considera que haya evidencia suficiente para afirmar que dichas variables influyan en la competencia estudiada. La tabla 4 muestra un resumen de lo aquí expresado.

Tabla 4. Relaciones estadísticamente significativas

\begin{tabular}{l|cl}
\multicolumn{1}{c|}{ Variables } & P valor & $\begin{array}{c}\text { Prueba } \\
\text { estadística }\end{array}$ \\
\hline $\begin{array}{l}\text { Sé si un virus computacional es } \\
\text { un problema de software o de } \\
\text { hardware. *Sexo }\end{array}$ & 0,014 & $\begin{array}{l}\text { Chi-cuadrado } \\
\text { de Pearson }\end{array}$ \\
\hline $\begin{array}{l}\text { Reconozco si el siguiente es un } \\
\text { problema de hardware o de } \\
\text { software: no se puede imprimir } \\
\text { porque faltan los drivers } \\
\text { (controladores) de la impresora. } \\
\text { *Programa de doctorado que } \\
\text { cursa }\end{array}$ & 0,038 & $\begin{array}{l}\text { Prueba exacta } \\
\text { de Fisher }\end{array}$ \\
\hline
\end{tabular}

Reconozco si el siguiente es un problema de hardware o de software: no se puede imprimir porque faltan los drivers

0,027

Chi-cuadrado (controladores) de la impresora. *Sexo

Conozco los términos comúnmente usados en las redes sociales (biografía, etiqueta, compartir, tweet, follow, hashtag, entre otros). *Programa de doctorado que cursa

Soy miembro de alguna comunidad o red de aprendizaje, utilizada para fines profesionales o personales. *Programa de doctorado que cursa
Soy miembro de alguna comunidad o red de aprendizaje, utilizada para fines profesionales o personales. * ¿En cuál institución 0,002 Prueba exacta de Fisher educativa?

\section{Soy miembro de alguna} comunidad o red de aprendizaje, utilizada para fines profesionales o personales. * Semestre que

0,006 Prueba exacta cursa

Conozco el tipo de licencia de uso, bajo el cual quedan sujetas mis publicaciones en internet y en 0,035 Chi-cuadrado redes sociales. * Sexo

Conozco cursos abiertos y recursos disponibles en internet para estudiar tópicos de mi interés, sean académicos o no. *Programa de doctorado que cursa

Conozco cursos abiertos y recursos disponibles en internet para estudiar tópicos de mi interés, sean académicos o no.

0,015 Prueba exacta *En cuál institución educativa? de Fisher

Sé respaldar la información en una computadora para no tener pérdidas, en caso de una falla 0 necesidad de borrar el disco duro.

0,007 Prueba exacta de Fisher

*Semestre que cursa

Fuente: elaboración propia.

\section{Conclusiones y recomendaciones}

Con relación al estado del conocimiento de las competencias digitales, se puede observar que el concepto se ha construido y enriquecido con el aporte de teóricos especialistas en el tema, así como de organismos internacionales. Esto hace que se supere el discurso estrictamente limitado a una perspectiva tecnológica y se contemple el asunto de una manera más integral, al incluir en sus definiciones distintos niveles de análisis: las dimensiones pedagógicas, comunicativas, informacionales y de gestión. En el mejoramiento de tales dimensiones reside la posibilidad de un tránsito exitoso de la sociedad de información a la sociedad del conocimiento. 
Sin embargo, en la realidad se presentan tensiones, vacíos e inconsistencias entre lo que establecen los organismos internacionales y los teóricos que estudian esta temática y lo que sucede en las aulas, en donde en ocasiones no se cuenta con los recursos tecnológicos mínimos para trabajar el desarrollo de competencias digitales. En ocasiones sí hay recursos tecnológicos, pero el desarrollo del proceso de enseñanza y aprendizaje parte de un modelo tradicional a la hora de favorecer la transmisión de conocimientos; también se encuentran hallazgos que reportan un hábil empleo de las TiC por parte de los estudiantes en un nivel básico, pero estas se utilizan de manera instrumental, lo cual no basta para constituir una base suficientemente sólida que fortalezca las actividades aptas para generar procesos de análisis, reflexión, identificación, explicación. En este sentido, no se cumplen los parámetros indicados que establecen los organismos internacionales. En cuanto al b-learning, se encontró que, si bien se considera la combinación de un modelo educativo, es necesario que las Tic y la acción de los profesionales se concentren en la construcción de entornos virtuales de aprendizaje, capaces de integrar los recursos, los propósitos y las intenciones pedagógicas (Sánchez Macías y Veytia Bucheli, 2017). A pesar de estas consideraciones, se encontró que la legislación mexicana no contempla el uso de las TIC, también denominado e-learning, como un requisito; se centra, más bien, en la cantidad de horas mínimas en las que el docente debe dirigir el proceso presencialmente. Vale la pena repensar, al menos en el caso mexicano, si las modalidades que utilizan las TIC tienen una finalidad educativa o si el propósito tiene fines únicamente comerciales. Quizás otras investigaciones pudieran abordar este tema más adelante.

El uso del instrumento elegido, validado mediante la técnica Delphi, presentó problemas en el momento de demostrar su consistencia y validez interna, cuando se confrontó con métodos estadísticos tales como el Alpha de Cronbach y el análisis factorial exploratorio, a través del método de componentes principales. Frente a las hipótesis propuestas, se rechazó que los estudiantes de doctorado tuvieran un nivel más alto de dominio de competencia digital, si se comparan sus resultados con los de los estudiantes de licenciatura (Zúñiga Lobato, 2016); no hay, entonces, una diferencia notoria, y además alcanzan apenas niveles de la mitad de la escala. En cuanto a la hipótesis que supone una relación estadísticamente significativa entre el dominio de competencia digital y la modalidad que se curse, se encontró evidencia parcial en varios indicadores que sugieren que dicha relación existe; sin embargo, estos indicios no pueden llevar a la generalización. Lo que sí se puede precisar es que el hecho de pertenecer a un programa que se imparte a distancia implica este tipo de habilidades en lo digital. Finalmente, no se pudo comprobar que el sexo o género del estudiante tuviera influencia en el dominio de las competencias digitales.

En cuanto a las hipótesis planteadas se considera lo siguiente:

No se encontró evidencia suficiente que establezca que el hecho de ser estudiante de doctorado implicara un alto nivel de dominio de competencia digital; en todo caso, existen otros factores que intervienen en esta relación y que otras investigaciones pueden determinar en el futuro. No se encontró evidencia para establecer una relación estadísticamente significativa entre el dominio de la competencia digital de estudiantes de doctorado y la modalidad que curse el encuestado. Sin embargo, en la muestra estudiada sí se encontraron mayores competencias digitales en los estudiantes de la modalidad virtual, si se comparan con los que estudian en modalidad mixta (b-learning). Finalmente, no existe evidencia suficiente para establecer una relación estadísticamente significativa entre el dominio de la competencia digital de los estudiantes de doctorado y el sexo de estos.

Es un error asumir que los niveles académicos y el tiempo transcurrido entre los niveles educativos garantizan, sin más, altos niveles de competencias digitales. El diagnóstico inicial, la intervención para su desarrollo y el seguimiento permanente es indispensable. Ya sea que se manifieste o no en el currículo, la competencia digital debe formar parte del perfil de egresado de cualquier graduado de pregrado y, por supuesto, del perfil de un 
investigador. El presente estudio sirve, además, para identificar la utilidad de un instrumento a la hora de medir la competencia digital y sus resultados. Esto es una gran ayuda en el momento de tomar decisiones y ejecutar acciones en materia de gestión educativa y pedagógica.

Otras investigaciones sobre este tema deberían considerar poblaciones más grandes con el fin de identificar si los resultados del análisis de consistencia y validez interna se deben al tamaño de la muestra. Asimismo, valdría la pena aplicar el instrumento de manera longitudinal, para identificar si el progreso del programa que se cursa influye en el desarrollo de competencias digitales.

\section{Referencias}

Álvarez-Flores, E. P.; Núñez-Gómez, P. y Rodríguez Crespo, C. (2017). Adquisición y carencia académica de competencias tecnológicas ante una economía. Revista Latina de Comunicación Social, 72, 540-559. doi:10.4185/RLCS, 72-2017-1178

Area, M. (2010). ¿Por qué formar en competencias informacionales y digitales en la Educación Superior? Revista de Universidad y Sociedad del Conocimiento, 7, 2-5. Monográfico Competencias informacionales y digitales en Educación Superior. Recuperado de http:// dx.doi.org/10.7238/rusc.v7i2.976

Arévalo Rodríguez, C. (2018). El b-learning y sus relaciones. Revista de la Universidad la Salle, 75, 83-103. Recuperado de https://revistas.lasalle.edu.co/index.php/ ls/article/view/5379

Arias, M.; Torres, T. y Yáñez, J. C. (2014). El desarrollo de competencias digitales en la educación superior. Historia y Comunicación Social, 19, 355- 366. Recuperado de http://revistas.ucm.es/index.php/HICS/article/ view/44963/42340

Barroso, C. (2013). Sociedad del conocimiento y entorno digital. Teoría de la Educación. Educación y Cultura en la Sociedad de la Información, 14(3), 61-86. Recuperado de http://www.redalyc.org/html/2010/201029582004/

Bonilla Tena, J. L. y Moctezuma Nava, A. (2017). Las competencias digitales y sus efectos en la práctica docente. Estudio de caso. Revista Multidisciplinaria de Avances de Investigación, 3(1), 121-141. Recuperado de http:// www.scielo.org.mx/pdf/ie/v12n59/v12n59a9.pdf

Carrasco Lozano, M. E.; Sánchez Olavarría, C. y Carro Olvera, A. (2015). Las competencias digitales en estu- diantes del posgrado en educación. Revista Lasallista de Investigación, 12(2), 10-18. Recuperado de http:// www.scielo.org.co/scielo.php?script=sci_arttext\&pi$\mathrm{d}=$ S1794-44492015000200001\&lng=en\&tlng=es

Carrera, X. y Coiduras, J. (2012). Identificación de la competencia digital del profesor Universitario: un estudio exploratorio en el ámbito de las Ciencias Sociales. Revista de Docencia Universitaria, 10(2), 273-298. Recuperado de https://repositori.udl.cat/bitstream/ handle/10459.1/47980/018608.pdf?sequence $=1$

Castells, M. (1997). La era de la información. Economía, sociedad y cultura. Madrid: Alianza.

Colás-Bravo, P.; Conde-Jiménez, J. y Reyes-de Cózar, S. (2017). Competencias digitales del alumnado no universitario. Revista Latinoamericana de Tecnología Educativa, 1(16), 7-20. Recuperado de http://dx.medra. org/10.17398/1695-288X.16.1.7

De Arco Paternin, L. K.; Barrios Barceló, H. D. y Parra Ortega, G. M. (2017). Análisis de factibilidad de un sistema de educación b-learning: caso de estudio Universidad de San Buenaventura. Revista Academia y Virtualidad, 10(2), 7-19. doi:10.18359/ravi.2706

De Pablos, J. (2010). Universidad y sociedad del conocimiento. Las competencias informacionales y digitales. En: Competencias informacionales y digitales en educación superior [Monográfico en línea]. Revista de Universidad y Sociedad del Conocimiento, 7(2), 6-16. Recuperado de http://openaccess.uoc.edu/webapps/ o2/bitstream/10609/2601/2/Monografic_esp.pdf

DeSeCo. (2000). La definición y selección de competencias clave. Resumen Ejecutivo. Recuperado de http:// deseco.ch/bfs/deseco/en/index/03/02.parsys.78532. downloadList.94248.DownloadFile.tmp/2005.dscexecutivesummary.sp.pdf

DIGCOMP. (2014). Marco europeo de competencias digitales. Recuperado de http://jakintza.net/wp-content/ uploads/DIGCOMP_Donostia_ES-Rev.pdf

Didriksson, A. (2007). Universidad y sociedad del conocimiento. México: Unesco-México.

Durat, J. M. y Mengual-Andrés, S. (2014). Impacto de la sociedad del conocimiento en la universidad y en la comunicación científica. Relieve, 20(2), 1-12. Recuperado de https://www.uv.es/RELIEVE/v20n2/RELIEVEv20n2_M4.pdf

Erstad, O. (2010). Educating the digital generation. Exploring media literacy for the 21st century. Nordic Journal of Digital Literacy, 5, 56-71. Recuperado de https://studentportalen.uu.se/uusp-filearea-tool/ download.action? nodeId=259042\&toolAttachmentId $=74649$ 
Frade, L. (2007). Nuevos paradigmas educativos. El enfoque por competencias en educación. CREFAL. Recuperado de http://repositoriodigital.academica.mx/ jspui/bitstream/987654321/21755/1/decisio16_saber2. pdf

Ferrari, A. (2013). DIGCOMP: A Framework for Developing and Understanding Digitals Competence in Europe. Luxemburgo: Publications Office of the European Union. doi: $10.2788 / 52966$

Flores, C. (2014). Competencia digital docente: desempeños didácticos en la formación inicial del profesorado. Revista Científica de Educación y Comunicación Hachetetepe, 9, 55-70. Recuperado de https://www. researchgate.net/publication/273440992_Competencia_digital_docente_desempenos_didacticos_en_la_ formacion_incial_del_profesorado

García-Sánchez, S. (2016). Educación a distancia, interactiva y ubicua para el aprendizaje de lengua inglesa. Revista Academia y Virtualidad, 9(1), 68-88. Recuperado de http://dx.doi.org/10.18359/ravi.1706

Gisbert, M. y Esteve, F. (2011). Digital learners: La competencia digital de los estudiantes universitarios. $\mathrm{La}$ Cuestión Universitaria, 7, 48-59.

Gisbert, M. (2011). El EES, características de un nuevo escenario para la formación. Diseño, producción y evaluación de un entorno telemático para la formación y reflexión del profesorado universitario para la implementación de EES. Sevilla: Universidad de Sevilla.

González-Yebra, Ó.; Aguilar, M. Á.; José Aguilar, F. y Matheu, M. L. (2018). Evaluación de entornos inmersivos $3 \mathrm{~d}$ como herramienta de aprendizaje b-learning. Educación XX1, 21(2), 417-440. doi:10.5944/educXX1.16204

Goodyear, P. y Ellis, R. (2008). University Students Approaches to Learning: Rethiking the Place of Technology. Distance Education, 29, 141-152.

Guzmán-Simón, F.; García-Jiménez, E. y López-Cobo, I. (2017). Undergraduate Students' Perspectives on Digital Competence and Academic Literacy in a Spanish University. Computers in Human Behavior, 74, 196-204. Recuperado de http://dx.doi.org/10.1016/j. chb.2017.04.040

Hardy, J., et.al. (2009). ICT \& the Student First Year Experience: A report from the LeaD Project. Bristol: JISC. Recuperado de http://www.jisc.ac.uk/whatwedo/ programmes/elearningpedagogy/lead.aspx.

Hernández Morales, O. C.; Amaya Espinosa, H. A.; Rodríguez Duque, L. F.; Gutiérrez Barrera, E. E. y Suárez Casas, V. (2016). Mapping Digital Competences of Modern Languages Students. Revista Academia y Vir- tualidad, 9(1), 89-104. Recuperado de http://dx.doi. org/10.18359/ravi.1404

Huerta, J., Pérez.; I. y Castellanos, A. (2000). Desarrollo curricular por competencias profesionales integrales. Educar. Revista de Educación, 13, 1- 11. Recuperado de https://www2.ufro.cl/docencia/documentos/Competencias.pdf

Islas Torres, C. y Franco Casillas, S. (2018). Detección de patrones en competencias digitales manifestadas por estudiantes universitarios. EDUTEC. Revista Electrónica de Tecnología Educativa, 64, 51-67. doi:https:/doi. org/10.21556/edutec.2018.64.1079

ITE. (2011). Competencia Digital. Recuperado de http:// recursostic.educacion.es/blogs/europa/media/blogs/ europa/informes/Competencia_Digital_Europa_ ITE_marzo_2011.pdf

Janssen, J. y Stoyanov, S. (2012). Institute for Prospective Technological Studies (IPTS), JRC, European Commission. Recuperado de http://ipts.jrc.ec.europa.eu/ publications/pub.cfm?id=5339.

Levy-Leboyer, C. (1997). Gestión de las competencias. Barcelona: Gestión 2000.

Littlejohn, A.; Beetham, H. y McGill, L. (2012). Learning at the digital frontier: a review of digital literacies in theory and practice. Journal of Computer Assisted Learning, 28, 1-10. doi: 10.1111/j.1365-2729.2011.00474.x

Margaryan, A. Littlejohn, A. y Vojt, G. (2011). Are Digital Natives a Muth or Reality? University students use of digital technologies. Computers and Education, 56, 429-440.

Mengual-Andrés, S.; Roig-Vila, R. y Blasco Mira, J. (2016). Delphi Study for the Design and Validation of a Questionnaire About Digital Competences in Higher Education. International Journal of Educational. Technology in Higher Education, 13(12), 1-11. doi: 10.1186/ s41239-016-0009-y

Mínguez, R. y Hernández, M. (2013). Hacia otra educación en la sociedad del conocimiento: cuestiones y propuestas pedagógicas. Teoría de la Educación. Educación y Cultura en la Sociedad de la Información, 14(3), 191-210. Recuperado de http://www.redalyc.org/ html/2010/201029582010/

Mortis Lozoya, S.; Valdés Cuervo, A.; Angulo Armenta, J.; García López, R. I. y Cuevas Salazar, O. (2013). Competencias digitales en docentes de educación secundaria. Municipio de un Estado del Noroeste de México. Perspectiva Educacional. Formación de profesores, 52(2), 135-153. doi: 10.4151/07189729-Vol.52-Iss.2-Art.174

Pérez, A. y Rodríguez, M. (2016). Evaluación de las competencias digitales autopercibidas del profesorado en 
educación primaria en Castilla y León. Revista de Investigación Educativa, 34(2), 399-415. Recuperado de http://www.redalyc.org/articulo.oa?id=283346043008

Perrenaud, P. (2007). Diez nuevas competencias para enseñar. Barcelona: Gráo.

Prendes Espinoza, M. P.; Solano Fernández, I. M.; Serrano Sánchez, J. L.; González Catalayud, V. y Román García, M. D. (2018). Entornos Personales de Aprendizaje para la comprensión y desarrollo de la Competencia Digital: análisis de los estudiantes universitarios en España. Educatio Siglo XXI, 36(2), 115-134. doi:https:// doi.org/10.6018/j/333081

Rangel, A. (2015). Competencias docentes digitales: propuesta de un perfil. Píxel-Bit. Revista de Medios y Educación, 46, 235-248.. doi: http://dx.doi.org/10.12795/ pixelbit.2015.i46.15

Roblizo, M. J. y Cózar Gutiérrez, R. (2015). Usos y competencias en TIC en los futuros maestros de educación infantil y primaria: hacia una alfabetización tecnológica real para docentes. Pixel-Bit. Revista de Medios y Educación, 47, 22-39. doi: http://dx.doi. org/10.12795/pixelbit.2015.i47.02

Røkenes, F. M. y Krumsvik, R. J. (2016). Prepared to teach ESL with ICT? A Study of Digital Competence in Norwegian Teacher Education. Computers and Education, 97, 1-20. doi: 10.1016/, Accepted Manuscript.

Salinas Ibáñez, J.; De Benito Crosetti, B.; Pérez Garcies, A. y Gisbert Cervera, M. (2018). Blended learning, más allá de la clase presencial. Revista Iboeroamericana de Educación a Distancia, 21(1), 195-213. doi:https://doi. $\operatorname{org} / 10.5944 /$ ried.21.1.18859

Sánchez, M.D. (2015). De la sociedad de la información a la sociedad del conocimiento. Utopía y Praxis Latinoamericana, 20, 125-130. Recuperado de http://www. redalyc.org/articulo.oa?id=27942241010

Sánchez Macías, A. y Veytia Bucheli, M. G. (2017). Integration of ICT in the Mexican Higher Education: The Case of the Virtual Environments of Learning. International Journal of Educational Excellence, 3(1), 63-77. doi:10.18562/ijee.024

Sharpe, R. (2010). Conceptualizing Differences in Learners Experiences of E-Learning: A Review of Contextual Models: Report of the Higher Education Academy Learner Difference (HEALD) Synthesis Project. Recuperado de http:// www.heacademy.ac.uk/assets/EvidenceNet/

Tobón, S. (2014). Currículo y ciclos propedéuticos desde la socioformación. Hacia un sistema educativo flexible y sistémico. México: Trillas.

Torrado, M.C. (1998). De las aptitudes a las competencias. Bogotá: Icfes.
Unesco. (2005). Hacia las sociedades del conocimiento. París: Ediciones Unesco. Recuperado de http://unesdoc. unesco.org/images/0014/001419/141908s.pdf

Unesco. (2008). Estándares de competencia en TIC para docentes. Londres: Ediciones Unesco. Recuperado de http://eduteka.icesi.edu.co/pdfdir/UNESCOEstandaresDocentes.pdf

Unesco. (2011). Unesco ICT. Competency Frameworkfor Teachers. París: Ediciones Unesco. Recuperado de http:// unesdoc.unesco.org/images/0021/002134/213475e.pdf

Veytia, M.G. (2013). Competencias básicas digitales en estudiantes de posgrado, Revista Electrónica de Investigación en Educación Superior, 1(1), 1-13. Recuperado de https://www.researchgate. net/profile/Maria_Veytia/publication/316065268_ Competencias_Basicas_Digitales_en_Estudiantes_de_Posgrado/links/58eea853a6fdcc61cc126892/ Competencias-Basicas-Digitales-en-Estudiantes-de-Posgrado.pdf

Villacrés Pástor, R.; Zea Pizarro, W. J.; Vaccaro Macías, V. I. y Avalos Moreno, E. (2017). El b-Learning como estrategia de aprendizaje en la educación superior. Revista Científica Mundo de la Investigación y el Conocimiento, 1(5), 359-378. doi:10.26820/recimundo/1.5.2017.359-378

Zabala, A. y Arnau, L. (2007). Once ideas clave. Cómo aprender y enseñar competencias. España: Gráo.

Zúñiga Lobato, J. I. (2016). Las competencias digitales en el perfil universitario: El caso de la Facultad de Pedagogía de la Universidad Veracruzana. Veracruz: Universidad Veracruzana. 